\title{
Maximal and explosive strength during COVID19: Impact on lower and upper limbs in Sport students
}

\author{
Ana Pereira and Luis Leitão
}

ana.fatima.pereira@ese.ips.pt ${ }^{1}$

Polytechnic Institute of Setubal - Higher School of Education

Life Quality Research Center (CIEQV), Portugal

\begin{abstract}
Introduction: The explosive strength of the upper and lower limbs are fundamental for health and well-being and functional performance (as sitting, avoiding a fall and/or an impact, get more agility and balance and mobility and coordination). Aim: Considering the widely established consequences of excessive screen time during COVID19 the present study aim to analyse the relation between maximal and power strength to understand that physical exercises could be a mediating factor for effect on and overall perception of well-being. Methodology: 24 students in Sports degree (age: $23.4 \pm 2.0$ years) were evaluated at maximum strength through the maximum repetition test (1RM) in the bench press (SUP) and leg press (PP) exercises and for explosive force and speed at the throwing of the Medicinal Ball (LBM), Horizontal Jump (IH) and the Sprint test 10 meters (10SP). Pearson's correlation $(\mathrm{p}<0.05)$ was used for the association between the variables. Results: The results obtained were: 1RMSUP: $62.8 \pm 26.3 \mathrm{~kg}$; 1RMPP: $239 \pm 90.1 \mathrm{~kg}$; $10 \mathrm{SP}: 2.1 \pm 0.14$ seconds; IH: $1.8 \pm 0.22$ meters; and, LBM: $4.5 \pm 0.84$ meters. A strong correlation was observed between strength and velocity in the lower limbs (10SP, IH and 1RMPP: between $\mathrm{r}=0.61$ and $\mathrm{r}=0.84$ ). Maximum strength of the lower limbs is fundamental for the performance in the 10SP and IH tests. The relationship between exercise and health should also aim at the greater contribution of muscle symmetry in relation to maximum and predominant performance. Ensuring a positive association in the prescription of regular physical exercise particularly in difficult phases such as the pandemic COVID19. The fact that the students attended classes mostly online seems to have contributed to a weakness in the strength of the lower limbs and may also be associated with a reduction in flexibility and body posture. Conclusion: The existing scientific evidence for the negative impact of excessive screen time on mental and physical health while providing new insights of physical exercise, specially strength training, during pandemic situation.
\end{abstract}

Publisher's Note: MDPI stays neutral with regard to jurisdictional claims in published maps and institutional affiliations.

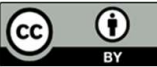

Copyright: (c) 2020 by the authors. Submitted for possible open access publication under the terms and conditions of the Creative Commons Attribution (CC BY) license (http://creativecommons.org/licenses /by/4.0/).

\footnotetext{
${ }^{1}$ Endereço eletrónico para correspondência
} 